\title{
PERBANDINGAN ANTARA KOMBINASI CROSSBODY STRETCHING DAN MOBILIZATON WITH MOVEMENT DENGAN KOMBINASI SLEEPER EXERCISE DAN MOBILIZATON WITH MOVEMENT DALAM MENINGKATAN ROM BAHU PADA KASUS GLENOHUMERAL INTERNAL ROTATION DEFICIT
}

\author{
Rizki Novrianti ${ }^{1}$, Dewa Putu Purwa Samatra ${ }^{2}$, Sugijanto $^{3}$, Luh Putu Ratna Sundari ${ }^{4}$, I Dewa \\ Ayu Inten Dwi Primayanti ${ }^{5}$, I Made Krisna Dinata ${ }^{6}$ \\ ${ }^{1}$ Program Studi Magister Fisiologi Keolahragaan Universitas Udayana, Denpasar \\ ${ }^{2}$ Departemen Neurologi, Fakultas Kedokteran, Universitas Udayana/RSUP Sanglah, Denpasar \\ ${ }^{3}$ Fakultas Fisioterapi Universitas Esa Unggul, Jakarta \\ 4,5,6 Departemen Ilmu Faal,Fakultas Kedokteran Universitas Udayana, Denpasar
}

E-Mail : rizkinovrianti2611@gmail.com

\begin{abstract}
ABSTRAK
Pendahuluan: Glenohumeral internal rotation deficit adalah suatu kondisi di mana internal rotasi bahu lebih kecil dibandingkan eksternal rotasi. Hal ini terjadi akibat adanya positional fault pada caput humerus yang mengalami antroposisi di mana posisi caput lebih ke arah superior pada fosa glenoid. Tujuan Penelitian: untuk membuktikan apakah kombinasi crossbody stretching dan mobilization with movement lebih baik daripada kombinasi sleepr exercise dan mobilization with movement dalam meningkatkan lingkup gerak sendi bahu dengan glenohumeral internal rotation deficit. Metode: Penelitian ini adalah penelitian uji klinis (clinical trial), yaitu penelitian dengan rancangan eksperimental pre test -post test group design. Jumlah sampel Kelompok I sebanyak 14 orang pasien diberikan intervensi dengan kombinasi crossbody stretching dan mobilization with movement sebanyak 3 kali seminggu selama 2 minggu, kemudian pada Kelompok II sebanyak 14 orang pasien diberikan kombinasi sleeper exercise dan mobilization with movement juga dilakukan sebanyak 3 kali seminggu selama 2 minggu. Pengukuran peningkatan nilai ROM bahu menggunakan goniometer. Hasil : 1) Terdapat peningkatan nilai ROM bahu pada Kelompok I,

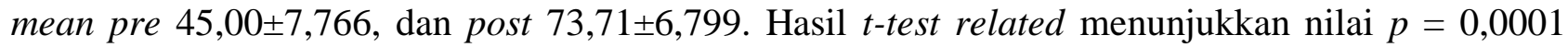
( $\mathrm{p}<0,05)$. (2) Terdapat peningkatan nilai ROM bahu pada Kelompok II, mean pre 47,29 $\pm 29,076$, dan post 76,71 $\pm 11,652$. Hasil $t$-test related menunjukkan nilai $p=0,0001(\mathrm{p}<0,05)$. (3) Tidak adanya perbedaan yang signifikan pada Kelompok I dan Kelompok II. Dilihat dari uji homogenitas, nilai $p>0,05$ maka hasil uji komparasi menggunakan nilai mean post-post dengan independent $t$ test yang menunjukkan nilai $\mathrm{p}=0,413$ ( $\mathrm{p}>0,05)$.
\end{abstract}

Kata kunci: Glenohumeral Internal Rotation Deficit, Crossbody Stretching, Mobilization with Movement, SleeperEexercise, Range of Motion. 


\title{
COMPARISON BETWEEN THE COMBINATION OF CROSSBODY STERTCHING AND MOBILIZATION WITH MOVEMENT WITH COMBINATION OF SLEEPER EXERCISE AND MOBILIZATION WITH MOVEMENT IN INCREASING SHOULDER ROM IN THE CASE OF GLENOHUMERAL INTERNAL ROTATION DEFICIT
}

\begin{abstract}
Background: Glenohumeral internal rotation deficit is a condition where the internal rotation of the shoulder is smaller than the external rotation. That occurs due to a positional fault at the head of the humerus which is anthropoid where the head position is more superior to the glenoid fossa. Purpose: to prove whether the combination of Crossbody stretching and mobilization with movement is better than the combination of sleeper exercise and mobilization with movement in increasing the scope of motion of the shoulder joint with a glenohumeral internal rotation deficit.

Method: This study is a clinical trial, which is a study with an experimental design pre-test post test group design. Number of samples Group I as many as 14 patients were given an intervention with a combination of crossbody stretching and mobilization with movement 3 times a week for 2 weeks, then in Group II as many as 14 patients were given a combination of sleeper exercise and mobilization with movement also performed 3 times a week for 2 weeks. Measurement of increased value of shoulder ROM using a goniometer. Result: (1) There was an increase in the value of shoulder ROM in Group I, the mean pre $45.00 \pm 7.766$, and the past $73.71 \pm 6.799$. The results of the related t-test showed the value of $p=0.0001(p<0.05)$. (2) There was an increase in shoulder ROM values in Group II, the pre-mean was 47.29 \pm 29.076 , and the post was $76.71 \pm$ 11.652. The results of the related t-test showed the value of $p=0.0001(p<0.05)$. (3) There aren't significant differences in Group I and Group II. Judging from the homogeneity test, the value of $p>$ 0.05 then the results of the comparison test use post-post comparative test with independent t-test which shows the value of $\mathrm{p}=0.413(\mathrm{p}>0.05)$.
\end{abstract}

Keywords: Glenohumeral Internal Rotation Deficit, Crossbody Stretching, Mobilization with Movement, Sleeper Exercise, Range of Motion.

\section{PENDAHULUAN}

Dalam aktivitas sehari-hari, sendi bahu (shoulder joint) merupakan salah satu anggota gerak yang memiliki mobilitas tinggi dan mudah mengalami cedera, sehingga pada pasien klinis sering ditemukan kumpulan gejala rasa nyeri pada bahu (rotator cuff disease, impingement syndromes, shoulder instabilities) yang dapat menyebabkan keterbatasan gerak hingga gangguan fungsi. ${ }^{1}$

Glenohumeral Internal Rotation Deficit (GIRD) adalah suatu kondisi yang mengakibatkan hilangnya rotasi internal sendi glenohumeral yang dilihat dari sisi kontralateral. Penyebab dari GIRD yang diketahui yaitu karena adanya tightness pada struktur posterior bahu sehingga terjadinya deselerasi bahu yang tidak tepat, lalu menyebabkan mikrotrauma berulang. ${ }^{2}$ Biasanya GIRD terjadi pada pemain softball atau pelempar karena melakukan gerakan overhead, namun GIRD juga banyak terjadi pada mahasiswa atau pekerja yang penyebabnya adalah pola aktivitas sehari-hari atau posisi tidur yang salah. ${ }^{3}$

Pada kondisi GIRD, ada beberapa jaringan yang mengalami gangguan (anatomic impairment) yaitu sendi, capsul ligament, saraf serta adanya muscle imbalance pada otot bahu, muscle imbalance 
ini sebagai dampak dari beberapa otot yang memendek seperti $m$. Subscapularis, $m$. Teres major, m. Pectoralis minor dan m. Latisimus dorsi, termasuk beberapa otot lainnya yang mengalami tightness yaitu $m$. Deltoid, $m$. Infraspinatus, dan $m$. Teres minor. ${ }^{4}$

Adanya kekakuan pada posterior capsule sehingga menyebabkan hilangnya gerakan fisiologis roll and glide pada caput humeri terhadap fosa glenoid ke arah posterior, kemudian adanya antroposisi pada bahu di mana posisi caput humerus lebih tinggi daripada posisi anatomi sebenarnya yang seharusnya terletak di tengah fosa glenoid sehingga terjadi keterbatasan gerak karena terjadi impingement shoulder dan rasa nyeri pada gerakan internal rotasi dari sendi glenoidalis. ${ }^{5}$

Kapsul glenoid mengalami kekakuan pada bagian posterior sebagai dampak dari berkurangnya gerakan/glide dari caput humeri pada sendi, ketika dilakukan gerakan secara berulang-ulang maka pada bagian anterior akan mengalami regangan yang berlebih/ overstretch, dalam keadaaan yang lama maka akan terjadi penurunan lingkup gerak sendi pada satu sisi atau pola non capsular pattern. ${ }^{6}$

Fisioterapi mempunyai peranan yang sangat besar dalam peningkatan lingkup gerak sendi (LGS) internal rotasi bahu pada kondisi glenohumeral internal rotation deficit. Pemilihan intervensi sangat mempengaruhi keberhasilan dari suatu rangkaian proses fisioterapi. Dalam kasus ini ada beberapa bentuk latihan yang dapat meningkatkan ROM bahu pada kasus GIRD seperti sleeper stretch, roll-over sleeper stretch, doorway stretch, crossbody stretch, pectoralis minor stretch, mobilization with movement dan rotator cuff and periscapular strengthening. ${ }^{7}$ Dalam penelitian ini, peneliti memilih intervensi mobilization with movement (MWM), crossbody stretching, dan sleeper exercise karena ingin mengombinasikan gerakan aktif dan pasif oleh pasien dan fisioterapi yang diharapkan akan menghasilkan hasil yang lebih efektif dalam meningkatkan ROM bahu pada kasus GIRD.

Mobilization with movement (MWM) merupakan aplikasi mobilisasi aksesori bebas nyeri dengan teknik pasif yang di lakukan oleh fisioterapi dan aktif yang dilakukan oleh pasien. ${ }^{1}$ Teknik ini sudah banyak digunakan untuk menangani berbagai macam disfungsi muskuloskeletal. Pemberian intervensi mobilization with movement memanfaatkan gerakan aktif co-contraction. Mobilization with movement (MWM) merupakan teknik manual terapi yang berdasarkan analisis dan koreksi dari setiap positional fault pada sendi. Teknik ini bertujuan untuk mengembalikan positional fault dari sendi dengan cara melakukan gerakan glide khusus secara manual pada sendi yang cedera dan menyesuaikan intensitas gerak. ${ }^{8}$

Pada penelitian sebelumnya, Philip McClure mengombinasikan intervensi sleeper exercise dan crossbody stretching untuk meningkatkan LGS internal rotasi pada bahu. Saheb et al mengatakan bahwa crossbody stretching lebih efektif daripada sleeper exercise dalam meningkatkan LGS internal rotasi bahu karena adanya penurunan ambang nyeri dan peningkatan ROM bahu sebanyak $90^{\circ}$. Sedangkan Kevin G Launder mengatakan bahwa sleeper exercise lebih efektif dalam meningkatkan LGS internal rotasi bahu. Namun, belum ada penelitian sebelumnya yang mengombinasikan kedua teknik stretching tersebut dengan mobilization with movement untuk meningkatkan LGS internal rotasi bahu. Sesuai pendapat yang diutarakan oleh Bryan Mulligan bahwa intervensi MWM akan memberikan hasil yang lebih efektif apabila ditambahkan dengan latihan fisik. ${ }^{9}$

\section{METODE PENELITIAN}

\section{A. Rancangan Penelitian}

Penelitian menggunakan desain eksperimental pre and post-test

\section{B. Tempat dan Waktu Penelitian}

Penelitian dilakukan di Poli fisioterapi Rumah Sakit Siaga Raya, Jakarta Selatan pada April - Mei 2019. Penelitian dilakukan dengan frekuensi 3 kali seminggu yang berlangsung selama 2 minggu. Sampel berjumlah 14 orang di masing-masing kelompok. 


\section{Populasi dan Sampel}

Populasi dari penelitian ini merupakan pasien dengan kondisi glenohumeral internal rotation deficit di RS. Siaga Raya pada bulan April-Mei 2019 yang berusia 18-50 tahun yang telah memenuhi kriteria inklusi dan eksklusi.

\section{Teknik Pengambilan Sampel}

Sampel berasal dari pasien umum yang datang ke RS Siaga Raya Jakarta Selatan. Pemilihan sampel dengan menggunakan teknik purposive sampling sesuai dengan kriteria penerimaan (inklusif), kriteria penolakan (eksklusif), dan kriteria drop out. Pembagian sampel yang telah memenuhi kriteria dibagi menjadi dua kelompok menggunakan simple random sampling, yaitu 14 sampel pertama sebagai kelompok I yang diberikan intervensi kombinasi mobilization with movement dengan crossbody stretching dan 14 sampel kedua sebagai kelompok II yang diberikan intervensi kombinasi mobilization with movement dengan sleeper exercise.

\section{HASIL PENELITIAN}

\section{Karakteristik Subyek}

Pada tabel 1 berisi distribusi karakteristik subyek yang menunjukkan total subyek penelitian adalah 28 orang $(n=28)$, dengan distribusi tiap kelompok I dan II berjumlah empat belas orang (100\%). Kelompok I dan II didominasi oleh perempuan. Distribusi usia pada kelompok I didominasi oleh kelompok usia 27-35 tahun sementara untuk kelompok II didominasi oleh kelompok usia 36-42 tahun. Deskripsi tentang berat badan kelompok I didominasi dengan kelompok berat badan dengan rentang 50-79 $\mathrm{kg}$ yang berjumlah 12 responden. Pada kelompok II, responden yang paling banyak adalah dengan kelompok berat badan dengan rentang 50-64 $\mathrm{kg}$ yang berjumlah 8 responden. Deskripsi tentang sisi dominan tubuh menunjukkan bahwa dari kedua kelompok sisi kanan tubuh lebih dominan daripada sisi kiri tubuh yaitu sebanyak $79 \%$.
Tabel 1

Karakteristik Subyek Kelompok I dan II Berdasarkan Jenis Kelamin, Usia Berat Badan, dan Sisi Dominan Tubuh

\begin{tabular}{cccc}
\hline \multirow{2}{*}{ Kategori } & \multicolumn{2}{c}{ Frekuensi (\%) } \\
\cline { 3 - 4 } & & $\begin{array}{c}\text { Kelompok } \\
\text { I }\end{array}$ & $\begin{array}{c}\text { Kelompok } \\
\text { II }\end{array}$ \\
\hline Jenis & Laki-laki & $6(43)$ & $6(43)$ \\
Kelamin & Perempuan & $8(57)$ & $8(57)$ \\
Usia & $18-26$ & $1(7)$ & $3(21)$ \\
(tahun) & $27-35$ & $7(50)$ & $4(29)$ \\
& $36-42$ & $2(14)$ & $5(36)$ \\
Berat & $43-50$ & $4(29)$ & $2(14)$ \\
Badan & $50-64$ & $6(43)$ & $8(57)$ \\
(kg) & $65-79$ & $6(43)$ & $5(36)$ \\
Sisi & $80-94$ & $2(14)$ & $1(7)$ \\
Dominan & Kanan & $11(79)$ & $11(79)$ \\
Tubuh & Kiri & $3(21)$ & $3(21)$ \\
\hline
\end{tabular}

\section{Uji Normalitas dan Homogenitas}

Pada tabel 2 berisi hasil uji normalitas pada data nilai ROM sebelum dan setelah perlakuan kelompok I dan kelompok II menggunakan Shapiro-Wilk test menghasilkan nilai $\mathrm{p}<0,05$ yang menunjukkan bahwa data berdistribusi normal. Selain itu, pada hasil uji homogenitas pada data nilai ROM sebelum perlakuan masing-masing kelompok, didapatkan hasil $\mathrm{p}=0,395(\mathrm{p}>0,05)$. Hal ini menunjukkan data bersifat homogen. Maka, uji hipotesis dilakukan dengan analisis statistik parametrik.

Tabel 2

Hasil Uji Normalitas dan Homogenitas Nilai ROM

\begin{tabular}{|c|c|c|c|}
\hline \multirow[b]{2}{*}{ Periode } & \multicolumn{2}{|c|}{ Shapiro Wilk Test* } & Levene's Test** \\
\hline & $\begin{array}{c}\text { Kelompok I } \\
\text { P }\end{array}$ & $\begin{array}{c}\text { Kelompok II } \\
\text { P }\end{array}$ & \\
\hline Sebelum & 0,997 & 0,826 & \\
\hline $\begin{array}{l}\text { Setelah } \\
\text { perlakuan }\end{array}$ & 0,459 & 0,057 & 0,395 \\
\hline
\end{tabular}


** Uji Homogenitas

\section{Uji Beda Hasil Pengukuran ROM Bahu}

Berdasarkan Tabel 3 di atas, hasil penelitian ini menunjukkan bahwa pada kelompok I, didapatkan nilai $\mathrm{p}=0,0001(\mathrm{p}<$ 0,05) sehingga dapat disimpulkan ada peningkatan ROM bahu pada kelompok I setelah diberikan intervensi kombinasi mobilization with movement dengan crossbody stretching.

Pada kelompok II didapatkan nilai $\mathrm{p}=$ 0,0001 ( $\mathrm{p}<0,05)$ sehingga dapat disimpulkan ada peningkatan ROM bahu pada kelompok II setelah diberikan intervensi kombinasi mobilization with movement dengan sleeper exercise.

Pada uji beda rerata sebelum perlakuan didapatkan nilai $\mathrm{p}=0,480$ dan rerata setelah perlakuan didapatkan nilai $\mathrm{p}=0,413$ yang berarti nilai $p>0,05$. Sehingga dapat disimpulkan bahwa tidak ada perbedaan yang signifikan antara pemberian kombinasi mobilization with movement dengan crossbody stretching dan pemberian kombinasi mobilization with movement dengan sleeper exercise dalam meningkatkan ROM bahu pada kasus glenohumeral internal rotation deficit.

\section{Tabel 3}

Hasil Uji Beda Pengukuran ROM Bahu

Sebelum dan Setelah Perlakuan Pada Kelompok I dan II

\begin{tabular}{cccc}
\hline \multirow{2}{*}{ Kelompok } & $\begin{array}{c}\text { Sebelum } \\
\text { perlakuan }\end{array}$ & $\begin{array}{c}\text { Setelah } \\
\text { perlakuan }\end{array}$ & \\
\cline { 2 - 3 } P-Value & Mean \pm SD & Mean $\pm \mathrm{SD}$ & \\
\hline I & $45,00 \pm 7,766$ & $73,71 \pm 6,799$ & $0,0001^{\mathrm{a}}$ \\
II & $47,29 \pm 9,076$ & $76,71 \pm 11,652$ & $0,0001^{\mathrm{a}}$ \\
P-Value & $0,480^{\mathrm{b}}$ & $0,413^{\mathrm{b}}$ & \\
\hline
\end{tabular}

a. paired sample t-test

b. independent t-test

\section{PEMBAHASAN}

Kombinasi Mobilization With Movement dan Crossbody Stretching dapat

\section{Meningkatkan ROM Bahu pada kasus Glenohumeral Internal Rotation Deficit}

Pada kelompok I dengan jumlah sampel sebanyak 14 orang diperoleh nilai peningkatan ROM internal rotasi bahu tertinggi dengan nilai selisih sebelum dan setelah perlakuan sebesar $41^{\circ}$ dan nilai terendah dengan nilai selisih sebelum dan setelah perlakuan sebesar 16. Kemudian dilakukan uji hipotesis I menggunakan paired sample t-test yang dapat dilihat dari nilai

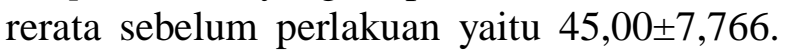
Kemudian nilai rerata setelah perlakuan sebesar 73,71 $\pm 6,799$. Berdasarkan paired sample t-test pada data tersebut maka didapat nilai $p$-value 0,0001 di mana $p<0,05$. Maka dapat disimpulkan bahwa kombinasi mobilization with movement dan crossbody stretching dapat meningkatkan ROM bahu pada kasus glenohumeral internal rotation deficit.

GIRD terjadi karena adanya tightness pada otot-otot posterior di mana adanya translasi caput humeri ke arah anterosuperior pada saat posisi bahu fleksi secara pasif. Peregangan struktur bahu posterior melalui teknik mobilisasi sendi bahu posterior akan memungkinkan kepala humerus berada ke arah posisi yang sesuai, yang memungkinkan artrokinematika glenohumeral menjadi normal dan mengurangi risiko kondisi yang berpotensi terjadi patologis ini. ${ }^{10}$

Hasil serupa juga ditemukan pada penelitian sebelumnya yang dilakukan oleh Manske et al yang melakukan perbandingan terhadap 2 kelompok, yaitu pemberian crossbody stretch pada kelompok I dan pemberian crossbody stretch dengan penambahan joint mobilization. Hasil yang didapatkan adanya peningkatan ROM internal rotasi bahu yang signifikan setelah diberikan latihan crossbody stretch dengan tambahan mobilisasi sendi bahu selama 4 minggu. ${ }^{11}$

Kombinasi Mobilization With Movement dan Sleeper Exercise meningkatkan ROM Bahu pada kasus Glenohumeral Internal Rotation Deficit 
Pada kelompok II dengan jumlah sampel sebanyak 14 orang diperoleh nilai peningkatan ROM internal rotasi bahu tertinggi dengan nilai selisih sebelum dan setelah perlakuan sebesar $45^{\circ}$ dan nilai terendah dengan nilai selisih sebelum dan setelah perlakuan sebesar 9. Kemudian dilakukan uji hipotesis II menggunakan paired sample t-test yang dapat dilihat dari nilai rerata sebelum perlakuan yaitu 47.29 99.076. Kemudian nilai mean setelah perlakuan sebesar 76.71 \pm 11.652 . Berdasarkan paired sample t-test pada data tersebut maka didapat nilai $P$-value 0,0001 di mana $\mathrm{p}<0,05$. Maka dapat disimpulkan bahwa kombinasi mobilization with movement dan sleeper exercise dapat meningkatkan ROM bahu pada kasus glenohumeral internal rotation deficit.

Keuntungan menggunakan latihan ini berupa penurunan nilai nyeri melalui mekanisme sebagai berikut; otot rotator cuff yang terlatih memberikan stabilitas caput humerus terhadap fossa glenoidalis, hal tersebut menyebabkan ketika lengan bergerak maka terjadi proteksi untuk menjaga celah dan menghindari benturan antara tuberculum major humeri dengan acromion. Latihan ini memberi efek regangan yang memberi peningkatan fleksibilitas jaringan pada bahu yang mengalami kekakuan dan berdampak terhadap penurunan nyeri.

Seperti pada penelitian sebelumnya yang dilakukan oleh Grow Kendall pada tahun 2010 yang melakukan penelitian selama 8-12 minggu terhadap atlet baseball yang mengalami GIRD dan didapatkan peningkatan ROM internal rotasi bahu dengan sleeper exercise. Beliau mengatakan bahwa latihan ini harus digunakan secara teratur dan dilakukan dengan benar untuk mencapai hasil yang lebih maksimal. Pada peningkatan range of motion bahu, penelitian ini menunjukkan perbedaan yang signifikan antara pre dan post intervensi terhadap gerak internal rotasi. Hal ini menunjukkan bahwa latihan tersebut memberi peningkatan terhadap lingkup gerak sendi bersamaan dengan peningkatan fleksibilitas yang terjadi pada kapsul sendi yang mengalami kekakuan. ${ }^{12}$

\section{Kombinasi Mobilization With Movement dan Crossbody Stretching lebih baik daripada Kombinasi Mobilization With Movement dan Sleeper Exercise meningkatkan ROM Bahu pada kasus Glenohumeral Internal Rotation Deficit}

Hasil perbandingan kedua intervensi menunjukkan bahwa tidak ada perbedaan yang signifikan antara pemberian kombinasi mobilization with movement dengan crossbody stretching dan pemberian kombinasi mobilization with movement dengan sleeper exercise dalam meningkatkan ROM bahu pada kasus glenohumeral internal rotation deficit.

Pada kombinasi mobilization with movement dan crossbody stretching maupun pada kombinasi mobilization with movement dan sleeper exercise keduanya memberikan efisiensi waktu dalam meningkatkan nilai ROM karena kombinasi intervensi tersebut memberikan perbaikan pada beberapa aspek dan mekanisme, seperti pada aspek biomechanic terjadi perbaikan kesalahan posisi (positional fault) pada komponen gerak persendian sehingga terjadi koreksi kesalahan posisi, aspek arthrokinematics terjadi melalui perbaikan propriosepsi dan perbaikan gerak fisiologi roll glide pada sendi glenohumeral dan perbaikan sirkulasi serta viskositas cairan sendi, aspek neurophysiology berkaitan dengan perubahan sistem inhibisi nyeri, melalui stimulasi mechanoreceptors yang kemudian menginhibisi rangsang pada nociseptive sehingga terjadi penurunan nyeri, aspek pshychology juga mempengaruhi, seperti berkurangnya ketakutan terhadap timbulnya rasa nyeri ketika bergerak.

Efek penggunaan metode MWM juga dipublikasikan oleh Ribeiro et al, metode dilakukan pada tiga puluh partisipan tanpa gejala atau keluhan bahu, pengukuran dilakukan menggunakan surface electromyography yang di letakan pada otot supraspinatus, infraspinatus, deltoidposterior, dan middle deltoid. Peserta melakukan empat set 10 repetisi abduksi dari scaption bahu dengan dan tanpa sustained glenohumeral postero-lateral glide. Hasil pengukuran di 
analisis multivariat dengan (MANOVA) untuk menilai efek dari arah pergerakan (abduksi dan scaption), dan kondisi (dengan dan tanpa postero-lateral glide) pada tingkat aktivitas masing-masing otot (variabel dependen). MANOVA secara signifikan dilanjutkan dengan analisis satu arah pada tiap varians. ${ }^{13}$

Peningkatan nilai ROM bahu dengan crossbody stretching terjadi karena adanya stabilisasi scapula yang secara otomatis dapat meningkatkan efektivitas peregangan pada daerah bahu posterior. Sedangkan peningkatan nilai ROM bahu dengan sleeper exercise terjadi disebabkan oleh metode yang tidak memberi rasa nyeri dan ketidaknyamanan yang minimal yang dihasilkan selama latihan peregangan. Sleeper exercise tidak menimbulkan spindle otot yang memungkinkan otot lebih rileks dan mencapai peregangan yang lebih besar yaitu peningkatan toleransi peregangan dan peningkatan rentang gerak yang mungkin terkait dengan efek analgesik. ${ }^{14}$

Keuntungan menggunakan teknik manual terapi terutama MWM adalah mengefisiensikan waktu pemulihan menjadi lebih singkat karena MWM memperbaiki kesalahan posisi (positional fault) yang memberi pengaruh pada penguluran otot dan kapsul sendi, sehingga memperbaiki aspek arthrokinematics. Mekanisme neurofisiologi berkaitan dengan MWM dan termasuk ke dalam perubahan sistem inhibisi nyeri, memungkinkan MWM mengurangi rasa sakit melalui stimulasi mechanoreceptors yang kemudian menginhibisi rangsang pada nociseptive. Selain efek neurofisiologi dan efek biomekanik, gerakan MWM yang diulang-ulang memungkinkan mengubah konsentrasi mediator anti inflamasi pada sendi, yang kemudian menghambat nosiseptor nyeri. Selanjutnya efek psikologis juga mempengaruhi, seperti berkurangnya ketakutan terhadap timbulnya rasa nyeri ketika bergerak. $^{15}$

\section{KETERBATASAN PENELITIAN}

Keterbatasan tersebut yaitu tidak adanya kontrol faktor genetik, struktur sendi, riwayat cedera responden serta aktivitas fisik atau pekerjaan dari responden di mana hal-hal tersebut dapat mempengaruhi perubahan nilai ROM selama penelitian.

\section{SIMPULAN}

1. Kombinasi mobilization with movement dan crossbody stretching meningkatkan ROM bahu pada kasus glenohumeral internal rotation deficit.

2. Kombinasi mobilization with movement dan sleeper exercise meningkatkan ROM bahu pada kasus glenohumeral internal rotation deficit.

3. Tidak ada perbedaan yang signifikan antara pemberian kombinasi mobilization with movement dengan crossbody stretching dan Kombinasi mobilization with movement dengan sleeper exercise dalam meningkatkan ROM bahu pada kasus glenohumeral internal rotation deficit.

\section{DAFTAR PUSTAKA}

1. Kisner, C., Colby, A. 2007. Therapeutic Exercise Fifth Edition, Philadhelpia: Davis Company

2. Johnson, J. E., Fullmer, J. A., Nielsen, C. M., Johnson, J. K., Moorman, C. T. 2018. Glenohumeral Internal Rotation Deficit and Injuries: A Systematic Review and Meta-analysis. USA: Campbell University

3. Kibler, W. B., Sciascia, A., Thomas, S. J. 2012. Glenohumeral Internal Rotation Deficit: Pathogenesis and Response to Acute Throwing. Sports Med Arthrosc. Vol 20, No 1

4. Kotagiri, S., Songa, A. K., Gad, M. V., Lad, J. 2018. Effectiveness of Mobilization with Exercise versus Internal Rotation MWM with Stretching in Patient with Glenohumeral Internal Rotation Deficit. International Archives of Integrated Medicine. Vol 5. Issue 5.

5. Lewis, S. J., Weright, C., Green, A. 2005. "Subacromial Impingement Syndrome," The Effect of Changing Posture on Shoulder Range of Movement. United Kingdom. Journal of 
Orthopaedic \& Sport Physical Therapy. Vol 35, No 2

6. Dharmawan, P. K., Tirtayasa, K., Wahyuddin., Ngurah, I. B., Sandi, I. N., Sugijanto. 2018. Kombinasi Caudal Traction dan Mobilization with Movement Lebih Baik Daripada Kombinasi Caudal Traction dan Scapular Stability Exercise dalam Meningkatan Kemampuan Fungsional Pada External Impingement Syndrome. Denpasar. Sport and Fitness Journal. Vol. 6, No.2

7. Miller, M., Woon, C. 2019. Glenohumeral Internal Rotation Deficit. United States: Orthopaedic Surgeons and Providers

8. Kotagiri, S., Songa, A. K., Gad, M. V., Lad, J. 2018. Effectiveness of Mobilization with Exercise versus Internal Rotation MWM with Stretching in Patient with Glenohumeral Internal Rotation Deficit. International Archives of Integrated Medicine. Vol 5. Issue 5.

9. Hing, W., Hall, T., Rivett, D., Vicenzino, B., Mulligan, B. 2015. The Mulligan Concept of Manual Therapy. Australia: National Library of Australia

10. Heyworth B. E., Williams R. J., 2009. Internal impingement of the shoulder. $A m$ J Sports Medicine;37:1024-1037

11. Manske, R. C., Meschke, M., Porter, A., Smith, B., Reiman., M. 2010. A Randomized Controlled Single-Blinded Comparison of Stretching Versus Stretching and Joint Mobilization for Posterior Shoulder Tightness Measured by Internal Rotation Motion Loss. Sports Health 2: 94-100

12. Kendall, G. 2010. The Sleeper Stretch: Effects on Range of Motion and Injury in Baseball Players. California: San Jose State University

13. Ribeiro, C. D., De-Castro, P. M., Sole, G., Vicenzino, B. 2015. The initial effect of a suistained glenohumeral posterolateral glide during elevation on shoulder muscle activity: a repeated measures study on asymptomatic shoulder. Science Direct. Vol. 22. No. 3:101-8

14. Laudner, K., Sipes, R., Wilson, J. 2008. The acute effects of Sleeper stretches on shoulder range of motion. Journal of Athletic Training, 43, 359-363

15. Junaedi, M. P., Adiatmika, I. P. G., Lesmana, S. I., Tirtayasa, K., Weta, I. W., Wahyuddin. 2019. Pelatihan Shoulder Girdle Dynamic Stabilization Lebih Baik Daripada Pelatihan Prone Scapular Stabilization Dalam Meningkatkan Kemampuan Fungsional Bahu Pasca Cedera Swimmer Shoulder Pada Atlet Renang Gaya Bebas di Kalimantan Barat. Denpasar. Sport and Fitness Journal. Vol.7, No.1

16. Cahyadi, M.W., Tianing, N.W., Dinata, I.M.K. 2018. Perbedaan Proprioceptive Neuromuscular Facilitation (Pnf) Stretching dan Ice Massage dalam Mencegah Terjadinya Delayed Onset Muscle Soreness (Doms) pada Remaja di Denpasar. Majalah Ilmiah Fisioterapi Indonesia. Vol.6, No.3 